\title{
Admission EEG findings in diverse paediatric cerebral malaria populations predict outcomes
}

\author{
Douglas G. Postels ${ }^{1,6^{*}}$, Xiaoting Wu ${ }^{2}$, Chenxi Li ${ }^{2}$, Peter W. Kaplan ${ }^{3}$, Karl B. Seydel ${ }^{4,5}$, Terrie E. Taylor ${ }^{4,5}$, \\ Youssef A. Kousa ${ }^{6}$, Richard Idro ${ }^{7}$, Robert Opoka ${ }^{7}$, Chandy C. John ${ }^{8}$ and Gretchen L. Birbeck ${ }^{9,10}$
}

\begin{abstract}
Background: Electroencephalography at hospital presentation may offer important insights regarding prognosis that can inform understanding of cerebral malaria (CM) pathophysiology and potentially guide patient selection and risk stratification for future clinical trials. Electroencephalogram (EEG) findings in children with CM in Uganda and Malawi were compared and associations between admission EEG findings and outcome across this diverse population were assessed. Demographic, clinical and admission EEG data from Ugandan and Malawian children admitted from 2009 to 2012 with CM were gathered, and survivors assessed for neurological abnormalities at discharge.

Results: 281 children were enrolled (Uganda $n=122$, Malawi $n=159$ ). The Malawian population was comprised only of retinopathy positive children (versus $72.5 \%$ retinopathy positive in Uganda) and were older (4.2 versus 3.7 years; $p=0.046$ ), had a higher HIV prevalence ( 9.0 versus $2.8 \% ; p=0.042$ ), and worse hyperlactataemia ( 7.4 versus $5.2 \mathrm{mmol} / \mathrm{L} ; \mathrm{p}<0.001$ ) on admission compared to the Ugandan children. EEG findings differed between the two groups in terms of average voltage and frequencies, reactivity, asymmetry, and the presence/absence of sleep architecture. In univariate analyses pooling EEG and outcomes data for both sites, higher average and maximum voltages, faster dominant frequencies, and retained reactivity were associated with survival (all $p<0.05)$. Focal slowing was associated with death (OR 2.93; $95 \% \mathrm{Cl} 1.77-7.30)$ and a lower average voltage was associated with neurological morbidity in survivors $(p=0.0032)$.
\end{abstract}

Conclusions: Despite substantial demographic and clinical heterogeneity between subjects in Malawi and Uganda as well as different EEG readers at each site, EEG findings on admission predicted mortality and morbidity. For CM clinical trials aimed at decreasing mortality or morbidity, EEG may be valuable for risk stratification and/or subject selection.

Keywords: Malaria, Paediatrics, Africa, Malawi, Uganda

\section{Background}

Cerebral malaria $(\mathrm{CM})$ is defined as an otherwise unexplained coma in a patient with malaria parasitaemia [1]. Despite improvements in anti-malarial treatment regimens, the mortality rate in tertiary care centres remains $15-25 \%$ and approximately one-third of survivors are left with neurological sequelae at hospital discharge

\footnotetext{
*Correspondence: dpostels@childrensnational.org

${ }^{6}$ Department of Neurology, Children's National Health System, 111

Michigan Avenue NW, Washington, DC 20010, USA

Full list of author information is available at the end of the article
}

including developmental or behavioural abnormalities, and epilepsy [2,3]. Single-site studies have suggested that admission electroencephalogram (EEG) may offer important insights into both prognosis $[4,5]$ and the pathophysiology of CM [2]. Several phase II and III clinical trials aimed at improving survival and neurologic outcomes from $\mathrm{CM}$ are ongoing or have been recently completed [6-9]. Future phase III clinical trials could potentially benefit from validation of a noninvasive biomarker that allows identification of children at high risk of death. Such a marker might allow for 
subject enrichment during enrollment or stratification of collected data.

EEG is not routinely available across Africa. Previously published single-site case series have reported a number of abnormalities in the EEGs of children with CM including diffuse slowing, atypical sleep elements (spindles and vertex waves), and epileptiform activity $[5,10$, 11]. In a case series of 65 Kenyan children with CM, a slower background frequency was significantly associated with an increased risk of death [5]. Burst-suppression was found in a higher proportion of children who died compared to those who lived, but the numbers of children with burst-suppression was small and the differences in proportions between outcome groups were not statistically significantly different. A report from Malawi identified a lack of variability and reactivity to painful stimulation as a risk factor for mortality [12]. A recently published study of acute magnetic resonance imaging and EEG findings in 168 Malawian children with CM determined that a slower background frequency was significantly associated with increased mortality risk [4]. No multi-site studies of EEG in CM have been published.

The epidemiology of CM is rapidly evolving due to climate change and successful control programs resulting in some regions with decreased disease burden, countered by other regions where incidence is constant or increasing [1]. Definitive clinical trials aimed at decreasing malaria morbidity and mortality will likely require multiple study sites both to assure access to adequate numbers of eligible children as well as improve the generalizability of results. To explore the potential value of EEG for subject selection or stratification in future clinical trials, admission EEG factors were compared between the two study sites, and the associations of these factors with death and neurodisability in Malawian and Ugandan children determined. This study's goal was to identify EEG factors associated with death or neurological disability that could potentially inform future clinical trials. Identification of EEG changes associated with mortality and morbidity that might allow further insight into the underlying pathophysiology of death and disability in children with CM were assessed.

\section{Methods}

Clinical and admission EEG data in consecutively admitted children with CM from Uganda and Malawi were gathered. Mulago Hospital is a large (1600 bed) Ugandan public tertiary care facility located in the country's capital, Kampala. Queen Elizabeth Central Hospital (QECH) is the largest public health care facility in Malawi and located in the country's commercial capital of Blantyre. Both hospitals are home to independent long-standing studies of severe malaria pathogenesis and natural history. Children 6 months to 15 years old, admitted to either Mulago or QECH with a clinical diagnosis of CM (Blantyre coma score $\leq 2$, Plasmodium falciparum on peripheral blood smear, and no other known aetiology of coma) between December 2008 and January 2012 were eligible for inclusion. All children included in this substudy were recruited for comprehensive projects studying CM pathogenesis and clinical epidemiology.

Nurse to patient ratios were high in both countries (one nurse to two patients or occasionally 1:1)-substantially higher than is the standard of routine care. In Malawi, children were hospitalized on a paediatric research ward dedicated to the study of children in coma, while in Uganda they were admitted to the high acuity ward (paediatric intensive care unit) with dedicated study nurses.

EEGs were recorded within $12 \mathrm{~h}$ of admission at both sites. All children were comatose (Blantyre Coma Score $\leq 2)$ at the time of recording. Malawi used a Ceegraph digital machine (BioLogic/Natus, Pleasanton, California) and Uganda an XLTEC 32 channel machine (Natus Medical Corporation, Pleasanton, California). EEG technicians used the international 10-20 system for electrode placement. Recording duration was $30 \mathrm{~min}$ or more, unless the patient became medically unstable or was otherwise unable to tolerate the procedure. EEG interpretations used for patient care were performed during hospitalization by study and non-study personnel to assess for non-convulsive status epilepticus or electrographic seizures. Research interpretations used for this study were performed after hospital discharge by a paediatric neurologist (DP, Uganda) or an epileptologist (GB and PK, Malawi) using Persyst Insight II (Persyst corporation, Prescott, Arizona). Interpreters were blinded to the child's outcome. Interpretations were scored on a standardized form with predetermined definitions for each finding. These included: a determination of average background frequency; average and maximal voltages (excluding vertex sharp waves); the absence or presence of spontaneous EEG variability; the absence or presence of sleep spindles; the absence or presence of vertex waves; a quantitation of the proportion of epochs with sleep spindles $(0,1-25 \%, 26-50 \%, 51-75 \%,>75 \%)$; identification and characterization of epileptiform activity; and determination of EEG reactivity. EEG technicians assessed reactivity by application of a painful stimulus (usually a sternal rub) to determine if changes in frequency or amplitude occurred. Previous experience with interpretation of EEGs in children with CM led us to characterize two types of reactivity, paradoxical or normal. EEG interpreters defined paradoxical reactivity as slowing in frequency or decrease in amplitude by more than $50 \%$ that occurred after application of a painful stimulus. Normal reactivity was defined as an increase in 
frequency or amplitude by more than $50 \%$ that occurred after stimulation. An electrographic seizure was defined as a rhythmic repetitive spike-wave discharge with an electrical field that evolved in frequency, morphology, or amplitude over at least $10 \mathrm{~s}$. Although several children had multiple EEGs performed during their hospital stay, only the first EEG obtained was used in this analysis as this would be the one most relevant for informing future clinical trials.

During hospitalization, clinical seizures were treated first with intravenous diazepam or intramuscular paraldehyde. If ictal phenomena were recurrent or prolonged, phenobarbital was added. Breakthrough seizures on phenobarbital were treated by adding phenytoin. Clinical complications were treated as they developed. Continuous EEG monitoring was not performed in either centre.

In the children who survived, outcome was determined at hospital discharge by parent interview and a neurological exam; examinations were performed by physicians in Uganda and by a physician or clinical officer in Malawi. Clinical officers are paramedical professionals who undergo 3 years of technical training after secondary school. They are largely trained to use an algorithmic approach to patient care for conditions commonly seen in their region. They are not explicitly trained to conduct a detailed neurologic assessment.

Children whose parents stated they were not back to normal (new motor, cognitive, or behavioural abnormalities), or children found to have new neurological signs on examination were classified as 'alive with sequelae'. Those with normal neurological exams and whose parents reported they were back to baseline were classified as 'normal'. Across institutions, there were no further specific criteria to determine whether a child should be classified as normal versus alive with sequelae.

\section{Statistical analysis}

Demographic factors, clinical characteristics and discharge outcomes of the study population were described using means (and standard deviations) or proportions. To evaluate differences between study site populations, comparisons were made in continuous and categorical EEG variables in Malawi and Uganda. Wilcoxon rank sum tests were used for comparisons of continuous data. Pearson's Chi square tests were used for categorical data where all cell counts were $\geq 5$; Fisher's exact tests were used to analyse categorical data with cell counts less than 5. Pooling data from Uganda and Malawi, univariate analyses of continuous EEG variables (e.g. frequency, amplitude) in children of differing outcomes were compared using Wilcoxon rank sum tests. Categorical EEG variables (e.g. asymmetry, reactivity, variability, presence or absence of electrographic seizures) in children of differing outcomes were compared using Pearson's Chi square or Fisher's exact test, as appropriate. A two-sided $\mathrm{p}<0.05$ was considered a statistically significant difference between groups.

\section{Results}

During the study period, 281 EEGs were performed and analysed, 122 from Uganda and 159 from Malawi. Tables 1 and 2 compare demographic, clinical, EEG and outcomes data between the two sites. The Malawian population was comprised only of retinopathy positive children (versus $72.5 \%$ in Uganda) and were older (4.2 versus 3.7 years; $\mathrm{p}=0.046)$, had a higher HIV prevalence $(9.0$ versus $2.8 \% ; \mathrm{p}=0.042$ ), and worse hyperlactataemia (7.4 versus $5.2 \mathrm{mmol} / \mathrm{L} ; \mathrm{p}<0.001)$ on admission than Ugandan children (Tables 1 and 2). In Uganda, 21 children (17.2\%) died and 44 of the 100 survivors (44.0\%) had neurological sequelae at hospital discharge. (In one Ugandan survivor, the presence or absence of neurological sequelae was unknown.) In Malawi, outcomes were better: 22 children (13.8\%) died, and $11.3 \%$ (16 of the 137 survivors) had neurological sequelae. There was no statistically significant difference in the mortality rates between Malawi and Uganda $(p=0.408)$. Rates of morbidity in survivors were significantly higher in Uganda than Malawi $(\mathrm{p}=0.002)$.

There were multiple statistically significant differences in admission EEGs when comparing Malawian and Ugandan children (Tables 1 and 2). Average voltage was lower and frequencies were slower in EEGs from Uganda compared to those from Malawi. EEG variability, sleep spindles, and vertex waves were significantly more common in Ugandan children, while EEGs from Malawian children were more likely to show asymmetry. There was no statistically significant difference in the proportion of children with electrographic seizures in the two locations.

Tables 3 and 4 delineate the univariate analyses of pooled EEG findings associated with mortality. Death was associated with a lower average voltage $(93.8 \mu \mathrm{V}$ in survivors compared to $69.9 \mu \mathrm{V}$ in those who died, $\mathrm{p}=0.0032$ ), lower maximum voltage (210.6 $\mu \mathrm{V}$ in survivors compared to $171.1 \mu \mathrm{V}$ in those who died, $\mathrm{p}=0.0089$ ), and slower dominant frequency $(2.2 \mathrm{~Hz}$ in survivors compared to $1.8 \mathrm{~Hz}$ in those who died, $\mathrm{p}=0.0030$ ). Focal slowing was associated with death (OR 2.93; 95\% CI 1.77-7.30) and reactivity with survival (OR for death 0.37 ; 95\% CI $0.18-0.79)$.

A univariate analysis of pooled EEG findings associated with neurological morbidity in survivors revealed that a higher average voltage was associated with a normal neurological outcome in survivors $(101.9 \mu \mathrm{V}$ in those with a normal outcome versus $70.1 \mu \mathrm{V}$ in those with neurological sequelae, $\mathrm{p}<0.0001$ ) (Tables 5 and 6 ). 
Table 1 Comparison of clinical and EEG characteristics (continuous variables) between Malawian and Ugandan children with cerebral malaria (value \pm SD) (denominators vary due to missing data)

\begin{tabular}{|c|c|c|c|c|c|}
\hline \multirow[t]{2}{*}{ Variable } & \multicolumn{2}{|c|}{ Uganda $(\mathrm{N}=122)$} & \multicolumn{2}{|c|}{ Malawi $(\mathrm{N}=159)$} & \multirow{2}{*}{$\begin{array}{l}p \text { value } \\
\text { for difference }\end{array}$} \\
\hline & $\mathrm{N}$ & Mean \pm SD & $\mathrm{N}$ & Mean \pm SD & \\
\hline Age (years) & 122 & $3.75 \pm 1.95$ & 159 & $4.23 \pm 2.27$ & 0.0463 \\
\hline Glucose (mg/dL) & 119 & $6.6 \pm 3.4$ & 159 & $7.1 \pm 3.7$ & 0.8200 \\
\hline $\begin{array}{l}\text { Parasitemia (parasites } / \mu \mathrm{L} \text { ) (geometric } \\
\text { mean) }\end{array}$ & 116 & $33,288.5$ & 148 & $33,239.2$ & 0.9961 \\
\hline Lactate (mmol/L) & 117 & $5.2(4.0)$ & 159 & $7.4(4.1)$ & $<0.0001$ \\
\hline Blantyre Coma Score (n/N, \%) & & & & & 0.91 \\
\hline 0 & & $9(7.4)$ & & $12(7.6)$ & \\
\hline 1 & & $57(46.7)$ & & $78(49.1)$ & \\
\hline 2 & & $56(45.9)$ & & $69(43.4)$ & \\
\hline Average voltage $(\mu \mathrm{V})$ & 117 & $65.77 \pm 31.84$ & 151 & $109.1 \pm 55.17$ & $<0.0001$ \\
\hline Maximum voltage $(\mu \mathrm{V})$ & 117 & $198.0 \pm 73.16$ & 152 & $209.9 \pm 88.62$ & 0.3866 \\
\hline Dominant frequency $(\mathrm{Hz})$ & 115 & $1.93 \pm 0.73$ & 148 & $2.34 \pm 1.09$ & 0.0132 \\
\hline
\end{tabular}

Table 2 Comparison of clinical and EEG characteristics (categorical variables) between Malawian and Ugandan children with cerebral malaria (denominators vary due to missing data)

\begin{tabular}{|c|c|c|c|}
\hline Variable & Uganda (n/N, \%) & Malawi (n/N, \%) & $\begin{array}{l}\text { p value } \\
\text { for difference }\end{array}$ \\
\hline Retinopathy positive & $87 / 120(72.5)$ & 159/159 (100) & - \\
\hline HIV reactivity & $3 / 109(2.8)$ & 13/144 (9.0) & 0.0423 \\
\hline Variability (\% with) & 73/119 (61.3) & $78 / 159(49.1)$ & 0.0418 \\
\hline Asymmetry (\% with) & $15 / 122(12.3)$ & 49/159 (30.8) & 0.0002 \\
\hline Electrographic seizures (\% with) & $9 / 122(7.4)$ & $22 / 159(13.8)$ & 0.0867 \\
\hline Spindles (\% with) & $71 / 116(61.2)$ & $65 / 159(40.9)$ & 0.0009 \\
\hline Vertex sharp waves (\% with) & $56 / 118(47.5)$ & $39 / 159(25.0)$ & $<0.0001$ \\
\hline Slowing location (\% focal) & $5 / 117(4.2)$ & 19/159 (11.9) & 0.0240 \\
\hline Normal reactivity (\% with increase in voltage and/or frequency with stimulus) & $4 / 113(3.5)$ & $41 / 153(26.8)$ & $<0.0001$ \\
\hline $\begin{array}{l}\text { Paradoxical reactivity (\% with decrease in voltage and/or frequency with } \\
\text { stimulus) }\end{array}$ & $40 / 113(35.4)$ & $27 / 153(17.6)$ & \\
\hline
\end{tabular}

\section{Discussion}

Despite the substantial noise of demographic and clinical heterogeneity between subjects in Malawi and Uganda as well as different EEG readers at each site, there is a clear signal that EEG findings on admission predict mortality and morbidity.

Admission EEG findings in children with CM from Uganda differ from those recorded in Malawi. Possible explanations for these differences may be specific to EEG (study technique, interpreter effect), intrinsic to the nature of any multi-centre study (studies obtained at different time points, different inclusion criteria) or could represent true differences between the Malawian and Ugandan paediatric CM populations.

EEG interpretation is a subjective process with no currently available tools for objective, reliable quantification of frequency, voltage, or any of the variables captured in this study. Although automated tools are available to aid interpretation, these are sensitive to artifact, creating both false positive and negative findings, when compared to human interpretation as the gold standard. Three interpreters reviewed the EEGs included here, which likely introduced variability into interpretations. Interrater correlation between EEG variables in often modest [13], but relying on a single reader limits external generalizability [14]. The imperative to improve EEG interrater reliability in the identification of triphasic waves, hypsarrhythmia and sleep architecture has recently resulted in efforts aimed at developing more standardized terminology and/or additional reader training for the identification of specific findings [15-18]. If EEG is to be used for stratification and/or risk adjustment in multisite clinical trials of $\mathrm{CM}$, improved standardization and/ 
Table 3 Univariate analysis: Comparison of continuous clinical and EEG variables by outcome (mortality) (mean \pm SD)

\begin{tabular}{|c|c|c|c|c|}
\hline Country & Clinical or EEG variable & Alive $(\mathrm{N}=101)$ & $\operatorname{Died}(\mathrm{N}=21)$ & p value \\
\hline \multirow[t]{7}{*}{ Uganda } & Age (years) & $3.8 \pm 1.9$ & $3.6 \pm 2.1$ & 0.77 \\
\hline & Glucose (mg/dL) & $6.8 \pm 3.3$ & $5.6 \pm 3.6$ & 0.2622 \\
\hline & $\begin{array}{l}\text { Parasitemia (parasites } / \mu \mathrm{LL}) \text { [geometric mean } \\
\quad \text { (coefficient of variation)] }\end{array}$ & $30,315.4(21.9)$ & $53,669.7(6.5)$ & 0.3463 \\
\hline & Lactate $(\mathrm{mmol} / \mathrm{L})$ & $4.9 \pm 3.9$ & $6.7 \pm 4.1$ & 0.0467 \\
\hline & Average voltage $(\mu \mathrm{V})$ & $68.9 \pm 31.9$ & $50.5 \pm 27.4$ & 0.018 \\
\hline & Maximum voltage $(\mu \mathrm{V})$ & $206.3 \pm 71.0$ & $158.0 \pm 71.9$ & 0.007 \\
\hline & Dominant frequency $(\mathrm{Hz})$ & $2.0 \pm 0.7$ & $1.6 \pm 0.9$ & 0.02 \\
\hline Country & Clinical or EEG variable & Alive $(\mathrm{N}=137)$ & Died $(N=22)$ & p value \\
\hline \multirow[t]{7}{*}{ Malawi } & Age (years) & $4.3 \pm 2.3$ & $4.1 \pm 2.2$ & 0.70 \\
\hline & Glucose (mg/dL) & $7.1 \pm 3.6$ & $7.4 \pm 4.1$ & 0.8675 \\
\hline & $\begin{array}{l}\text { Parasitemia (parasites } / \mu L) \text { [geometric mean } \\
\quad \text { (coefficient of variation)] }\end{array}$ & $31,053.5(25.4)$ & $50,153.1(13.6)$ & 0.4189 \\
\hline & Lactate $(\mathrm{mmol} / \mathrm{L})$ & $7.2 \pm 4.1$ & $8.6 \pm 3.8$ & 0.0827 \\
\hline & Average voltage $(\mu \mathrm{V})$ & $112.2 \pm 54.3$ & $89.3 \pm 58.2$ & 0.08 \\
\hline & Maximum voltage $(\mu \mathrm{V})$ & $213.8 \pm 88.4$ & $184.3 \pm 88.2$ & 0.17 \\
\hline & Dominant frequency $(\mathrm{Hz})$ & $2.4 \pm 1.1$ & $1.9 \pm 0.9$ & 0.05 \\
\hline Country & Clinical or EEG variable & Alive $(\mathrm{N}=238)$ & Died $(N=43)$ & $p$ value \\
\hline \multirow[t]{7}{*}{ Uganda + Malawi } & Age (years) & $4.0 \pm 2.1$ & $3.8 \pm 2.1$ & 0.3459 \\
\hline & Glucose (mg/dL) & $7.0 \pm 3.5$ & $6.5 \pm 4.0$ & 0.5049 \\
\hline & $\begin{array}{l}\text { Parasitemia (parasites } / \mu L) \text { [geometric mean } \\
\quad \text { (coefficient of variation)] }\end{array}$ & $30,731.7(23.5)$ & $51,793.8(9.0)$ & 0.2168 \\
\hline & Lactate (mmol/L) & $6.2 \pm 4.2$ & $7.7 \pm 4.0$ & 0.0170 \\
\hline & Average voltage $(\mu \mathrm{V})$ & $93.8 \pm 50.8$ & $69.9 \pm 49.0$ & 0.0032 \\
\hline & Maximum voltage $(\mu \mathrm{V})$ & $210.6 \pm 81.4$ & $171.1 \pm 80.6$ & 0.0089 \\
\hline & Dominant frequency $(\mathrm{Hz})$ & $2.2 \pm 1.0$ & $1.8 \pm 0.9$ & 0.0030 \\
\hline
\end{tabular}

or development of validated sensitive and specific EEG interpretation software will be needed.

Despite these challenges, it is possible that the differences seen in admission EEGs between Malawian and Ugandan children represent intrinsic electrophysiological differences between populations. In terms of pathophysiological insights, many of the EEG findings described in this study are seen in other aetiologies of paediatric coma. EEG findings in children with non-malarial central nervous system infections are considered non-specific as to aetiology (e.g. viral versus bacterial) and consist of generalized delta waves [19], as was seen in these study subjects. This pattern implies that large areas of subcortical white matter are functionally abnormal [20]. Generalized slowing is seen more commonly in disorders primarily affecting white matter [21].

In a previous study of 201 children in coma in Italy, 26 of 77 children with central nervous system bacterial or viral infections had convulsions, though the authors did not clarify whether seizure activity was clinical, electrographic, or both [19]. Clinical seizures are very common in CM. In this study, non-continuous electrographic seizures captured on a 30 min EEG were documented in only $11.0 \%$ of subjects and were not associated with mortality or morbidity on pooled univariate analysis.

This study has several limitations. Continuous EEG monitoring was not performed, which likely led to a lack of sensitivity for ascertaining transient events. In paediatric traumatic brain injury, subclinical electrographic seizures are common, and the combination of clinical and electrographic seizures may occur in up to $77.3 \%$ of patients [14]. Studies of comatose children in paediatric intensive care units without restriction by coma aetiology reveal a $7 \%$ risk of subclinical electrographic seizures [22], a proportion similar to that seen in this study's subjects. It is not possible to know if continuous EEG sampling would have modified the associations found here.

The analysis of EEG factors associated with neurological morbidity was complicated by a non-standard definition of this outcome across sites. For example, children with mild ataxia that was resolving were coded as 
Table 4 Comparison of categorical demographic and EEG variables by outcome (mortality) (OR, 95\% Cl)

\begin{tabular}{|c|c|c|c|c|c|c|}
\hline Country & Clinical or EEG variable & $\begin{array}{l}\text { Children } \\
\text { with variable who } \\
\text { were alive } \\
(\mathrm{N}, \%)\end{array}$ & $\begin{array}{l}\text { Children } \\
\text { with variable } \\
\text { who died } \\
(\mathrm{N}, \%)\end{array}$ & Odds ratio ${ }^{a}$ & $\begin{array}{l}95 \% \\
\text { confidence } \\
\text { interval }\end{array}$ & $\mathrm{p}$ value \\
\hline \multirow[t]{12}{*}{ Uganda } & Total N (122) & 101 & 21 & & & \\
\hline & Retinopathy positive & $71(70.3)$ & $16(73.2)$ & 1.63 & $0.5,5.3$ & 0.41 \\
\hline & HIV reactivity & $3(3.0)$ & $0(0.0)$ & & & \\
\hline & Variability & $62(61.4)$ & $11(52.4)$ & 0.64 & $0.25,1.65$ & 0.35 \\
\hline & Asymmetry & $13(12.9)$ & $2(9.5)$ & 0.71 & $0.15,3.42$ & 0.67 \\
\hline & Electrographic seizures (present) & $8(7.9)$ & $1(4.8)$ & 0.58 & $0.07,4.9$ & 0.62 \\
\hline & Spindles (present) & $60(59.4)$ & $11(52.4)$ & 0.64 & $0.25,1.66$ & 0.36 \\
\hline & Vertex sharp waves & $47(46.5)$ & $9(42.9)$ & 0.79 & $0.31,2.07$ & 0.64 \\
\hline & Focal slowing & $3(2.9)$ & $3(14.3)$ & 5.27 & $0.98,28.3$ & 0.052 \\
\hline & Reactivity (normal + paradoxical) & 40 (39.6) & $4(19.1)$ & 0.306 & $0.09,0.98$ & 0.046 \\
\hline & $\begin{array}{l}\text { Normal reactivity (increase in voltage and/or } \\
\text { frequency with stimulus) }\end{array}$ & $37(36.6)$ & $3(14.3)$ & 1.02 & $0.09,10.46$ & 0.55 \\
\hline & $\begin{array}{l}\text { Paradoxical reactivity (decrease in voltage and/or } \\
\text { frequency with stimulus) }\end{array}$ & $3(2.97)$ & $1(4.76)$ & 0.25 & $0.07,0.91$ & 0.09 \\
\hline \multirow[t]{12}{*}{ Malawi } & Total N (159) & 137 & 22 & & & \\
\hline & Retinopathy positive & $137(100)$ & $22(100)$ & & & \\
\hline & HIV reactivity & $12(9.7)$ & $1(5.0)$ & 0.49 & $0.06,4.0$ & 0.5065 \\
\hline & Variability & $71(51.8)$ & $7(31.8)$ & 0.43 & $0.17,1.13$ & 0.087 \\
\hline & Asymmetry & $40(29.2)$ & $9(40.9)$ & 1.68 & $0.66,4.23$ & 0.27 \\
\hline & Electrographic seizures present & $16(11.7)$ & $6(27.3)$ & 2.84 & $0.97,8.3$ & 0.06 \\
\hline & Spindles present & $58(42.3)$ & $7(31.8)$ & 0.64 & $0.24,1.66$ & 0.35 \\
\hline & Vertex sharp waves & $37(27.0)$ & $2(9.1)$ & 0.27 & $0.06,1.21$ & 0.09 \\
\hline & Focal slowing (focal versus gen) & $14(10.2)$ & $5(22.7)$ & 2.58 & $0.83,8.08$ & 0.10 \\
\hline & Reactivity (normal + paradoxical) & $62(45.3)$ & $6(27.3)$ & 0.45 & $0.17,1.2$ & 0.12 \\
\hline & $\begin{array}{l}\text { Normal reactivity (increase in voltage and/or } \\
\text { frequency with stimulus) }\end{array}$ & $37(27.0)$ & $4(18.2)$ & 0.51 & $0.16,1.63$ & 0.77 \\
\hline & $\begin{array}{l}\text { Paradoxical reactivity (decrease in voltage and/or } \\
\text { frequency with stimulus) }\end{array}$ & $25(18.2)$ & $2(9.1)$ & 0.37 & $0.08,1.75$ & 0.42 \\
\hline \multirow[t]{12}{*}{ Uganda + Malawi } & Total N (281) & 238 & 43 & & & \\
\hline & Retinopathy positive & $208(87.4)$ & $38(88.4)$ & 1.32 & $0.44,3.98$ & 0.62 \\
\hline & HIV reactivity & $15(6.7)$ & $1(3.5)$ & 0.49 & $0.06,3.91$ & 0.5072 \\
\hline & Variability & $133(55.9)$ & $18(41.9)$ & 0.552 & $0.29,1.07$ & 0.077 \\
\hline & Asymmetry & $53(22.3)$ & $11(25.6)$ & 1.20 & $0.57,2.54$ & 0.634 \\
\hline & Electrographic seizures present & $24(10.1)$ & $7(16.3)$ & 1.73 & $0.69,4.32$ & 0.24 \\
\hline & Spindles present & $118(49.6)$ & $18(41.9)$ & 0.696 & $0.36,1.34$ & 0.28 \\
\hline & Vertex sharp waves & $84(35.3)$ & $11(25.6)$ & 0.614 & $0.29,1.28$ & 0.19 \\
\hline & Focal slowing & $17(7.1)$ & $8(18.6)$ & 2.93 & $1.76,7.3$ & 0.02 \\
\hline & Reactivity (normal + paradoxical) & $102(42.9)$ & $10(23.3)$ & 0.374 & $0.18,0.79$ & 0.010 \\
\hline & $\begin{array}{l}\text { Reactivity (increase in voltage and/or frequency } \\
\text { with stimulus) }\end{array}$ & $40(16.8)$ & $5(11.6)$ & 0.477 & $0.17,1.31$ & 0.79 \\
\hline & $\begin{array}{l}\text { Paradoxical reactivity (decrease in voltage and/or } \\
\text { frequency with stimulus) }\end{array}$ & $62(26.1)$ & $5(11.6)$ & 0.308 & $0.11,0.83$ & 0.13 \\
\hline
\end{tabular}

a Odds of death of children having the EEG feature divided by the odds of death of children without the EEG feature

"normal" in Malawi, but "abnormal" in Uganda. Future studies comparing EEG factors associated with neurological morbidity should standardize criteria to define neurosequelae. Children were classified as having neurological morbidity at discharge. Since neurological sequelae at discharge may clear over time, or epilepsy 
Table 5 Univariate analysis: comparison of continuous clinical and EEG variables by outcome (neurological morbidity in survivors) (mean \pm SD)

\begin{tabular}{|c|c|c|c|c|}
\hline Country & Clinical or EEG variable & Alive and normal $(\mathrm{N}=56)$ & $\begin{array}{l}\text { Alive with sequelae } \\
(\mathrm{N}=44)\end{array}$ & $p$ value \\
\hline \multirow[t]{7}{*}{ Uganda } & Age (years) & $3.8 \pm 1.7$ & $3.8 \pm 2.2$ & 0.5312 \\
\hline & Glucose (mg/dL) & $7.2 \pm 3.3$ & $6.4 \pm 3.4$ & 0.1376 \\
\hline & $\begin{array}{l}\text { Parasitemia (parasites/ } \mu \mathrm{L} \text { ) [geometric mean } \\
\text { (coefficient of variation)] }\end{array}$ & $31,931.6(23.3)$ & $31,434.9(18.7)$ & 0.9755 \\
\hline & Lactate (mmol/L) & $4.6 \pm 3.7$ & $5.3 \pm 4.2$ & 0.4449 \\
\hline & Average voltage $(\mu \mathrm{V})$ & $74.0 \pm 32.1$ & $63.6 \pm 30.8$ & 0.0723 \\
\hline & Maximum voltage $(\mu \mathrm{V})$ & $213.8 \pm 71.2$ & $199.1 \pm 70.3$ & 0.3809 \\
\hline & Dominant frequency $(\mathrm{Hz})$ & $2.0 \pm 0.7$ & $2.0 \pm 0.6$ & 0.9210 \\
\hline Country & Clinical or EEG variable & $\begin{array}{l}\text { Alive and normal } \\
(\mathrm{N}=121)\end{array}$ & $\begin{array}{l}\text { Alive with sequelae } \\
(\mathrm{N}=16)\end{array}$ & $p$ value \\
\hline \multirow[t]{7}{*}{ Malawi } & Age (years) & $4.3 \pm 2.3$ & $3.5 \pm 1.9$ & \\
\hline & Glucose (mg/dL) & $6.9 \pm 2.9$ & $8.3 \pm 7.0$ & 0.6468 \\
\hline & $\begin{array}{l}\text { Parasitemia (parasites/ } \mu \mathrm{L}) \text { [geometric mean } \\
\text { (coefficient of variation)] }\end{array}$ & $28,148.2(27.4)$ & $73,486.0(10.4)$ & 0.1988 \\
\hline & Lactate (mmol/L) & $7.0 \pm 4.0$ & $8.4 \pm 4.8$ & 0.3023 \\
\hline & Average voltage $(\mu \mathrm{V})$ & $114.5 \pm 54.2$ & $91.5 \pm 52.6$ & 0.2178 \\
\hline & Maximum voltage $(\mu \mathrm{V})$ & $217.4 \pm 86.3$ & $180.0 \pm 103.1$ & 0.1185 \\
\hline & Dominant frequency $(\mathrm{Hz})$ & $2.4 \pm 1.1$ & $2.1 \pm 1.3$ & 0.1550 \\
\hline Country & Clinical or EEG variable & $\begin{array}{l}\text { Alive and normal } \\
(\mathrm{N}=177)\end{array}$ & $\begin{array}{l}\text { Alive with sequelae } \\
(\mathrm{N}=60)\end{array}$ & p value \\
\hline \multirow[t]{7}{*}{ Uganda + Malawi } & Age (years) & $4.2 \pm 2.2$ & $3.7 \pm 2.1$ & 0.0723 \\
\hline & Glucose (mg/dL) & $7.0 \pm 3.0$ & $6.9 \pm 4.7$ & 0.1999 \\
\hline & $\begin{array}{l}\text { Parasitemia (parasites/ } \mu \mathrm{L}) \text { [geometric mean } \\
\text { (coefficient of variation)] }\end{array}$ & $29,312.6(25.57)$ & $38,422.1(16.66)$ & 0.4876 \\
\hline & Lactate $(\mathrm{mmol} / \mathrm{L})$ & $6.3 \pm 4.0$ & $6.1 \pm 4.5$ & 0.5321 \\
\hline & Average voltage $(\mu \mathrm{V})$ & $101.9 \pm 51.9$ & $70.1 \pm 38.4$ & $<0.0001$ \\
\hline & Maximum voltage $(\mu \mathrm{V})$ & $216.3 \pm 81.8$ & $194.6 \pm 78.5$ & 0.0943 \\
\hline & Dominant frequency $(\mathrm{Hz})$ & $2.3 \pm 1.0$ & $2.0 \pm 0.8$ & 0.0524 \\
\hline
\end{tabular}

may appear after a delay of months, misclassification may have occurred. Since post-CM epilepsy can develop months after hospitalization, this study could not identify acute EEG characteristics that are predictors of later developing epilepsy. Future studies should consider ascertainment of admission EEG factors associated with long-term neurological disability. In younger patients, post-CM developmental disabilities may be difficult to detect and only become clear as the patient ages, when the survivor's developmental milestones diverge from those of their unaffected peer group. Identification of EEG changes in children at higher risk of a long-term adverse outcome may allow focus of limited resources (physiotherapy, palliative care) to those at highest risk.

Retinopathy negative children were not represented in Malawi, as children from this site were enrolled in a parent study whose primary interest was retinopathy positive CM. Since one-third of children with clinical CM are retinopathy negative, the population from Malawi may not be representative of the clinical spectrum of children with this illness.

Identification of EEG factors associated with death and long-term adverse neurological outcome may allow insights into whether these outcomes share a common pathophysiology. Since seizures are considered primarily a gray matter-based abnormality, while slowing and decreased amplitudes are primary due abnormalities in the thalamo-cortical circuits (white matter based), it is possible that interventions successful in reducing rates of one outcome (mortality) may not lead to a change in the proportion of children with the other endpoint (e.g. an increase in the proportion of survivors with neurological disabilities). 
Table 6 Comparison of categorical demographic and EEG variables by outcome (neurological morbidity in survivors) (OR, 95\% Cl)

\begin{tabular}{|c|c|c|c|c|c|c|}
\hline Country & Clinical or EEG variable & $\begin{array}{l}\text { Children with variable who } \\
\text { were alive with sequelae } \\
(\mathrm{N}, \%)\end{array}$ & $\begin{array}{l}\text { Children with variable who } \\
\text { were alive without sequelae } \\
(\mathrm{N}, \%)\end{array}$ & Odds ratio $^{a}$ & $\begin{array}{l}95 \% \\
\text { confidence } \\
\text { interval }\end{array}$ & $p$ value \\
\hline \multirow[t]{12}{*}{ Uganda } & Total N (101) & & & & & \\
\hline & Retinopathy positive & $32(72.7)$ & $38(69.1)$ & 1.19 & $0.49,2.86$ & 0.6930 \\
\hline & HIV reactivity & $3(6.9)$ & 0 & & & \\
\hline & Variability & $28(63.6)$ & $34(64.2)$ & 0.98 & $0.43,2.25$ & 0.9581 \\
\hline & Asymmetry & $4(9.1)$ & $9(16.1)$ & 0.52 & $0.15,1.83$ & 0.3089 \\
\hline & $\begin{array}{l}\text { Electrographic seizures } \\
\text { (present) }\end{array}$ & $3(6.8)$ & $5(8.9)$ & 0.75 & $0.17,3.31$ & 0.7002 \\
\hline & Spindles (present) & $26(61.9)$ & $34(64.2)$ & 0.91 & $0.39,2.10$ & \\
\hline & Vertex sharp waves & $22(51.2)$ & $25(47.2)$ & 1.17 & $0.52,2.63$ & 0.6972 \\
\hline & Focal slowing & 0 & $2(3.8)$ & & & \\
\hline & $\begin{array}{l}\text { Reactivity (normal + paradoxi- } \\
\text { cal) }\end{array}$ & $15(37.5)$ & $25(49.0)$ & 0.62 & $0.27,1.45$ & 0.2730 \\
\hline & $\begin{array}{l}\text { Normal reactivity (increase in } \\
\text { voltage and/or frequency } \\
\text { with stimulus) }\end{array}$ & $2(5.0)$ & $1(1.9)$ & 2.08 & $0.18,24.40$ & 0.4128 \\
\hline & $\begin{array}{l}\text { Paradoxical reactivity (decrease } \\
\text { in voltage and/or frequency } \\
\text { with stimulus) }\end{array}$ & $13(32.5)$ & $24(47.1)$ & 0.56 & $0.24,1.35$ & 0.1895 \\
\hline \multirow[t]{11}{*}{ Malawi } & Total N (137) & & & & & \\
\hline & HIV reactivity & $1(7.1)$ & $11(10.0)$ & 0.69 & $0.08,5.81$ & 0.7347 \\
\hline & Variability & $7(43.8)$ & $64(52.9)$ & 0.69 & $0.24,1.98$ & 0.4932 \\
\hline & Asymmetry & $7(43.8)$ & $33(27.3)$ & 2.07 & $0.72,6.02$ & 0.1797 \\
\hline & Electrographic seizures present & $6(37.5)$ & $10(8.3)$ & 6.7 & $2.0,22.1$ & 0.002 \\
\hline & Spindles present & $5(31.3)$ & $53(43.8)$ & 0.58 & $0.19,1.78$ & 0.3438 \\
\hline & Vertex sharp waves & $1(6.3)$ & $36(29.8)$ & 0.16 & $0.02,1.24$ & 0.0788 \\
\hline & Focal slowing (focal versus gen) & $4(25.0)$ & $10(8.3)$ & 3.7 & $1.01,13.6$ & 0.0491 \\
\hline & $\begin{array}{l}\text { Reactivity (normal + paradoxi- } \\
\text { cal) }\end{array}$ & $6(37.5)$ & $56(48.3)$ & 0.64 & $0.22,1.89$ & 0.4209 \\
\hline & $\begin{array}{l}\text { Normal Reactivity (increase in } \\
\text { voltage and/or frequency } \\
\text { with stimulus) }\end{array}$ & $5(31.3)$ & $32(27.6)$ & 0.94 & $0.29,2.98$ & 0.3837 \\
\hline & $\begin{array}{l}\text { Paradoxical reactivity (decrease } \\
\text { in voltage and/or frequency } \\
\text { with stimulus) }\end{array}$ & $1(6.3)$ & $24(20.7)$ & 0.25 & $0.03,2.06$ & 0.2025 \\
\hline \multirow[t]{12}{*}{ Uganda + Malawi } & Total N (281) & & & & & \\
\hline & Retinopathy positive & $48(80.0)$ & $159(90.3)$ & 0.43 & $0.19,0.96$ & 0.0390 \\
\hline & HIV reactivity & $4(7.0)$ & $11(6.6)$ & 1.06 & $0.33,3.48$ & 0.9190 \\
\hline & Variability & $35(58.3)$ & $98(56.3)$ & 1.09 & $0.59,1.97$ & 0.7862 \\
\hline & Asymmetry & $11(18.3)$ & $42(23.7)$ & 0.72 & $0.34,1.51$ & 0.3875 \\
\hline & Electrographic seizures present & $9(15.0)$ & $15(8.5)$ & 1.91 & $0.79,4.62$ & 0.1529 \\
\hline & Spindles present & $31(53.5)$ & $87(50.0)$ & 1.15 & $0.63,2.08$ & 0.6493 \\
\hline & Vertex sharp waves & $23(38.9)$ & $61(35.1)$ & 1.18 & $0.64,2.18$ & 0.5875 \\
\hline & Focal slowing & $4(6.8)$ & $12(6.9)$ & 0.98 & $0.30,3.17$ & 0.9756 \\
\hline & $\begin{array}{l}\text { Reactivity (normal + paradoxi- } \\
\text { cal) }\end{array}$ & $21(37.5)$ & $81(48.5)$ & 0.64 & $0.34,1.19$ & 0.1543 \\
\hline & $\begin{array}{l}\text { Reactivity (increase in voltage } \\
\text { and/or frequency with } \\
\text { stimulus) }\end{array}$ & $7(12.5)$ & $33(19.8)$ & 0.52 & $0.21,1.29$ & 0.2856 \\
\hline & $\begin{array}{l}\text { Paradoxical reactivity (decrease } \\
\text { in voltage and/or frequency } \\
\text { with stimulus) }\end{array}$ & $14(25.0)$ & $48(28.7)$ & 0.72 & $0.35,1.46$ & 0.9846 \\
\hline
\end{tabular}

\footnotetext{
${ }^{a}$ Odds of disability of children having the EEG feature divided by the odds of disability of children without the EEG feature
} 


\section{Conclusions}

In children with CM, death is associated with patterns on admission EEG. Findings increasing the risk of death include a lower average voltage, lower maximum voltage, slower dominant frequencies, focal slowing, and a lack of reactivity. For $\mathrm{CM}$ clinical trials aimed at decreasing mortality, EEG may be valuable for risk stratification and/ or subject selection.

\begin{abstract}
Authors' contributions
DGP conceived and designed the study, interpreted the data, and wrote the first draft of the manuscript; XW analysed and interpreted the data; $\mathrm{CL}$ analysed and interpreted the data; PWK acquired and interpreted the data; KBS acquired and interpreted the data; TET acquired and interpreted the data; YAK interpreted the data; RI acquired and interpreted the data; RO acquired and interpreted the data; CCJ conceived the study and interpreted the data; GLB conceived and designed the study, and interpreted the data. All authors revised the manuscript critically for important intellectual content; gave final approval of the version to be published; and agree to be accountable for all aspects of the work in ensuring that questions related to the accuracy or integrity of any part of the work are appropriately investigated and resolved. All authors read and approved the final manuscript.
\end{abstract}

\section{Author details}

${ }^{1}$ International Neurologic and Psychiatric Epidemiology Program, Michigan State University, 909 Fee Road, 324 West Fee Hall, East Lansing, MI 48824, USA. ${ }^{2}$ Department of Epidemiology and Biostatistics, Michigan State University, 909 Fee Road, Room B601, East Lansing, MI 48824, USA. ${ }^{3}$ Department of Neurology, Johns Hopkins University, 4940 Eastern Avenue, Baltimore, MD 21224, USA. ${ }^{4}$ Blantyre Malaria Project, University of Malawi College of Medicine, Blantyre, Malawi. ${ }^{5}$ Department of Osteopathic Medical Specialties, College of Osteopathic Medicine, Michigan State University, East Lansing, MI 48824, USA. ${ }^{6}$ Department of Neurology, Children's National Health System, 111 Michigan Avenue NW, Washington, DC 20010, USA. ${ }^{7}$ Department of Paediatrics and Child Health, Makerere University College of Health Sciences, Kampala, Uganda. ${ }^{8}$ Indiana University School of Medicine, 1044 W. Walnut Street, Rm 402-D, Indianapolis, IN 46202, USA. ${ }^{9}$ Epilepsy Division, Department of Neurology, University of Rochester, 265 Crittenden Blvd, CU 420694, Rochester, NY 14642, USA. ${ }^{10}$ UTH Neurology Research Office, Nationalist Rd, PO Box UTH 11, Lusaka, Zambia.

\section{Acknowledgements}

The authors thank the children and their parents and guardians who took part in this study. The authors thank the Global Health Uganda and Blantyre Malaria Project study teams who took part in this project. Ward accommodation and essential support for this study was provided by the Department of Paediatrics of the University of Malawi College of Medicine, the Malawi-Liverpool-Wellcome Trust, Queen Elizabeth Central Hospital (Malawi), the Mulago Hospital Paediatrics Department (Uganda), and Makerere University Department of Child Health and Paediatrics (Uganda). Scientific (medical) writers: none.

\section{Competing interests}

The authors declare they have no competing interests.

\section{Availability of data and materials}

The datasets generated and/or analysed during the current study are not publicly available but are available from the corresponding author on reasonable request.

\section{Consent for publication}

Not applicable.

\section{Ethics approval and consent to participate}

The parent studies included EEG collection, interpretation, and analysis, and were reviewed and approved by ethics boards at Makerere University (Uganda), University of Malawi, Michigan State University, and University of Minnesota. Informed consent was obtained from guardians upon parent study entry.

\section{Funding}

Research reported in this publication was supported by the National Institute of Neurological Disorders and Stroke of the National Institutes of Health under award numbers K23NS046086 (GLB), R01NS055349 (CJ), and D43NS078280

(CJ). The content is solely the responsibility of the authors and does not necessarily represent the official views of the National Institutes of Health. The funding sources had no role in design of the study and collection, analysis, and interpretation of data and in writing the manuscript.

\section{Publisher's Note}

Springer Nature remains neutral with regard to jurisdictional claims in published maps and institutional affiliations.

Received: 29 January 2018 Accepted: 9 May 2018

Published online: 22 May 2018

\section{References}

1. WHO. World malaria report 2008. Geneva: World Health Organization; 2008

2. Birbeck GL, Molyneux ME, Kaplan PW, Seydel KB, Chimalizeni YF, Kawaza $K$, et al. Blantyre malaria project epilepsy study (BMPES) of neurological outcomes in retinopathy-positive paediatric cerebral malaria survivors: a prospective cohort study. Lancet Neurol. 2010;9:1173-81.

3. Postels DG, Taylor TE, Molyneux M, Mannor K, Kaplan PW, Seydel KB, et al. Neurologic outcomes in retinopathy-negative cerebral malaria survivors. Neurology. 2012;79:1268-72.

4. Seydel KB, Kampondeni SD, Valim C, Potchen MJ, Milner DA, Muwalo FW, et al. Brain swelling and death in children with cerebral malaria. N Engl J Med. 2015;372:1126-37.

5. Crawley J, Smith S, Muthinji P, Marsh K, Kirkham F. Electroencephalographic and clinical features of cerebral malaria. Arch Dis Child. 2001;84:247-53.

6. Birbeck G. A safety and feasibility study of enteral LVT vs. standard of care for seizure control in pediatric CM. Bethesda: NIH/NINDS; 2013-2016.

7. Epicentre. Evaluation of the efficacy and safety of inhaled nitric oxide as adjunctive treatment for cerebral malaria in children. Medecins Sans Frontières.

8. Taylor T. Treating brain swelling in pediatric cerebral malaria. Bethesda: NIH/NIAID; 2016-2018.

9. Birbeck $\mathrm{G}$. Aggressive antipyretics for fever reduction in CNS malaria. Bethesda: NIH/NINDS; 2018

10. Birbeck G, Taylor T, Molyneux M, Mwandira E, Jalfuli M, Kaplan P. EEG correlates in acute cerebral malaria. American Clinical Neurophysiology Society Annual Meeting: 2008, Savannah; 2008 (Abstract 23).

11. Crawley J, Smith S, Kirkham F, Muthinji P, Waruiru C, Marsh K. Seizures and status epilepticus in childhood cerebral malaria. Q J Med. 1996;89(8):591-7.

12. Mallewa M, Birbeck GL. The EEG of tropical encephalopathies. J Clin Neurophysiol. 2013;30:531-8.

13. Abend NS, Gutierrez-Colina A, Zhao H, Guo R, Marsh E, Clancy RR, et al. Interobserver reproducibility of electroencephalogram interpretation in critically ill children. J Clin Neurophysiol. 2011;28:15-9.

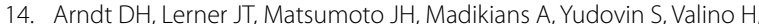
et al. Subclinical early posttraumatic seizures detected by continuous EEG monitoring in a consecutive pediatric cohort. Epilepsia. 2013;54:1780-8.

15. Foreman B, Mahulikar A, Tadi P, Claassen J, Szaflarski J, Halford JJ, et al. Generalized periodic discharges and 'triphasic waves': a blinded evaluation of inter-rater agreement and clinical significance. Clin Neurophysiol. 2016;127:1073-80.

16. Mytinger JR, Hussain SA, Islam MP, Millichap JJ, Patel AD, Ryan NR, et al. Improving the inter-rater agreement of hypsarrhythmia using a simplified EEG grading scale for children with infantile spasms. Epilepsy Res. 2015;116:93-8.

17. Halford JJ, Shiau D, Desrochers JA, Kolls BJ, Dean BC, Waters CG, et al. Inter-rater agreement on identification of electrographic seizures and periodic discharges in ICU EEG recordings. Clin Neurophysiol. 2015;126:1661-9. 
18. Wendt SL, Welinder P, Sorensen HB, Peppard PE, Jennum P, Perona P, et al. Inter-expert and intra-expert reliability in sleep spindle scoring. Clin Neurophysiol. 2015;126:1548-56.

19. Fois A, Malandrini F. Electroencephalographic findings in pediatric cases of coma. Clin Electroencephalogr. 1983;14:207-13.

20. Sutter R, Kaplan PW. Clinical and electroencephalographic correlates of acute encephalopathy. J Clin Neurophysiol. 2013;30:443-53.
21. Hussain E, Nordli D. EEG patterns in acute pediatric encephalopathies. J Clin Neurophysiol. 2013;30:539-44.

22. Shewmon DA. Coma prognosis in children. Part II: clinical application. J Clin Neurophysiol. 2000;17:467-72.
Ready to submit your research? Choose BMC and benefit from:

- fast, convenient online submission

- thorough peer review by experienced researchers in your field

- rapid publication on acceptance

- support for research data, including large and complex data types

- gold Open Access which fosters wider collaboration and increased citations

- maximum visibility for your research: over $100 \mathrm{M}$ website views per year

At BMC, research is always in progress.

Learn more biomedcentral.com/submissions 